
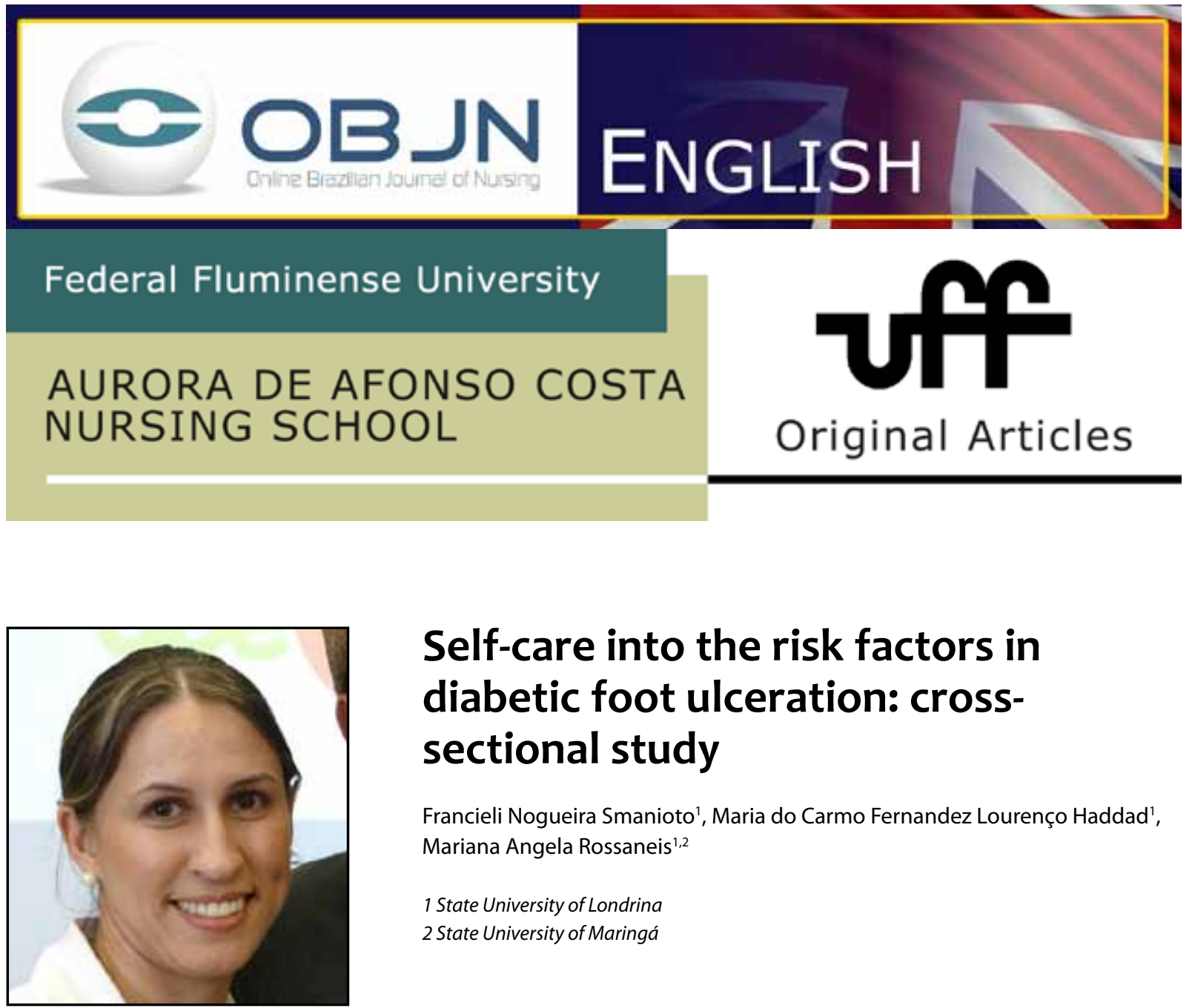

\title{
Self-care into the risk factors in diabetic foot ulceration: cross- sectional study
}

\author{
Francieli Nogueira Smanioto', Maria do Carmo Fernandez Lourenço Haddad', \\ Mariana Angela Rossaneis ${ }^{1,2}$ \\ 1 State University of Londrina \\ 2 State University of Maringá
}

\section{ABSTRACT}

Aim: To analyze the implications of self-care on the risk factors of ulceration in the feet of patients with diabetes mellitus, related to dermatology, orthopedic, neurological and vascular alterations. Method: Cross-sectional study, involving 1,515 patients with diabetes mellitus type 2, older than 40 years, enrolled in basic health units. Results: The prevalence of feet at risk of ulceration was $12.3 \%$. Changes in tibial and dorsalis pedis pulses, the altered capillary filling, the presence of bony prominences, hallux valgus, claw and hammer toes and the loss of protective sensation in the feet were associated with the risk of ulceration. Discussion: The prevalence of feet at risk of ulceration was considered high and is related to different dermatological, vascular and neuropathic factors permeated by the self-care factor. Conclusions: The prevention of alterations in the diabetic foot involves maintenance of glycemic control and specific foot care.

Descriptors: Diabetes Mellitus; Diabetic Foot; Risk Grade; Nursing. 


\section{INTRODUCTION}

Diabetes mellitus (DM) is a rising disease and has a growing high impact because of its high morbidity and high social and financial costs. The foot is one of its major complications, characterized by sores resulting from neurological, vascular and biomechanical changes often associated with infections ${ }^{(1)}$.

The diabetic foot can be classified as neuropathic, ischemic or neuro ischemic. Diabetic neuropathy is the main risk factor for foot ulceration and affects $30 \%$ to $70 \%$ of patients. The risk of developing this pathology becomes even greater when associated with peripheral arterial disease ${ }^{(2)}$. A chronic complication, with a high degree of mutilation, the diabetic foot is the cause of more than $70 \%$ of nontraumatic amputations of the lower limbs, resulting in high social and economic impact for both health systems and the population ${ }^{(3)}$.

The main factors for the prevention of this problem in patients with DM are regular inspection of the feet and footwear, the identification and classification of risk of ulceration, continuing education of the patient and family, and the training of health professionals for the management of diabetic foot and treatment of non-ulcerative changes ${ }^{(1)}$.

The investment in financial and human resources in the implementation of programs and specialized services in the care of the diabetic foot with a multidisciplinary team approach can reduce amputation rates by up to $85 \%{ }^{(1)}$.

Self-care practices are essential for the prevention of foot lesions in patients with DM, but are difficult to follow since they require changes in habits and due to the denial that the individual feels about the possibility of being affected by the complications of this disease ${ }^{(3)}$.

This study aimed to analyze the implications of self-care on the risk factors of ulceration in the feet of patients with DM, related to dermatology, orthopedic, neurological and vascular alterations.

The researchers' hypothesis of this study is that this danger is associated with socioeconomic factors, lifestyle and self-care practices with feet.

\section{METHOD}

An exploratory descriptive cross-sectional study, conducted with DM patients registered in all 38 Basic Health Units (BHU) in the urban area of the city of Londrina (PR, Brazil).

The sample size calculation was performed based on population data from the Brazilian Institute of Geography and Statistics (IBGE) distributed by $\mathrm{BHU}$, applying the estimate that 11\% of the population over 40 years old has diabetes mellitus ${ }^{(4)}$. The sample size was calculated using Epi Info version 3.5.3 software, using a prevalence of $50 \%$ and a sampling error of $5 \%$.

The selection of participants was done through simple random stratified sampling from the record in the Registration and Monitoring of Hypertensive Diabetics System (HIPERDIA) and data on SAUDEWEB program drug dispense report. The contact with diabetic patients to carry out the invitation to participate in the research was conducted via telephone or by home visits by health units' community agents.

Diabetes mellitus type 2 (DM2) patients, aged over 40 years, with logical reasoning and judgment preserved, were included in the study. Exclusion criteria were diabetics on dialysis, with previous amputations at any level of the lower limbs, and individuals who did not have autonomy to walk.

Data collection took place from October 2011 to August 2012, in the BHUs, on dates and times previously scheduled with individuals 
who agreed to participate. All study participants signed and received a copy of the Instrument of Consent.

For data collection we used an instrument developed by Bortoletto ${ }^{(5)}$, adapted to contain demographic and socioeconomic items, data on self-care practices with feet and skin and orthopedic, neurological and vascular abnormalities identified on clinical examination. Data collection was performed by the study researchers.

On examination of the feet, the observed dermatological aspects were onychomycosis, interdigital ringworm, keratoses and calluses, and skin moisture; of orthopedic disorders the presence of hallux valgus, claw toes, hammer toes and bony prominences were analyzed. The assessment of vascular abnormalities was made by palpation of the dorsal pedis and posterior tibial pulses. For the identification of diabetic neuropathy, we used the test of Semmes-Weinstein at 10 grams, because it is a low cost instrument, of easy access and high specificity, and of predictive value ${ }^{(6)}$.

The classification risk of ulceration was performed as shown in Chart $1^{(7)}$ :

Chart 1. Approach and clinical follow-up of patients with diabetes mellitus based on degree of risk of ulceration according to the Adult Health Clinical Protocol, Londrina (PR). Londrina, Paraná, Brazil, 2012.

\begin{tabular}{|c|c|c|}
\hline $\begin{array}{c}\text { Ulcera- } \\
\text { tion Risk }\end{array}$ & Alterations & $\begin{array}{c}\text { Approach and clinical } \\
\text { follow-up }\end{array}$ \\
\hline \multirow[t]{2}{*}{ Level 0} & \multirow{2}{*}{$\begin{array}{l}\text { Neuropathy } \\
\text { absent } \\
\end{array}$} & $\S$ Health education \\
\hline & & $\S$ Annual evaluation \\
\hline \multirow[t]{3}{*}{ Level 1} & \multirow{3}{*}{$\begin{array}{l}\text { Neuropathy } \\
\text { present }\end{array}$} & $\S$ Health education \\
\hline & & $\begin{array}{l}\S \text { Use of proper foo- } \\
\text { tware }\end{array}$ \\
\hline & & $\S$ Semiannual evaluation \\
\hline \multirow[t]{3}{*}{ Level 2} & \multirow{3}{*}{$\begin{array}{l}\text { Neuropathy, } \\
\text { signs of peri- } \\
\text { pheral vascular } \\
\text { disease and/or } \\
\text { deformities in } \\
\text { the feet }\end{array}$} & $\S$ Health education \\
\hline & & $\begin{array}{l}\text { § Use of appropriate/ } \\
\text { special footwear, insoles, } \\
\text { orthotics }\end{array}$ \\
\hline & & § Quarterly evaluation \\
\hline
\end{tabular}

\begin{tabular}{|l|l|l|}
\hline Level 3 & Amputation / & $\S$ Health education \\
\cline { 3 - 3 } & $\begin{array}{l}\text { previous alce- } \\
\text { ration }\end{array}$ & $\begin{array}{l}\text { § Use of appropriate/ } \\
\text { special footwear, insoles, } \\
\text { orthotics }\end{array}$ \\
\cline { 3 - 3 } & & $\S$ bimonthly evaluation \\
\hline
\end{tabular}

Source: Adult Health Clinical Protocol: hypertension, diabetes and dyslipidemia, 2006 (7).

To analyze the prevalence ratio (PR), the risk of ulceration was categorized as low risk of ulceration, including the levels 0 and 1 , and high risk of ulceration for levels 2 and 3.

Data collection was recorded directly in the Epi Info program database, a check of this was made at the end of each evaluation, with a second review at the end of the collection period, to avoid typographical errors and incomplete data.

To identify associations between variables, we used the chi-square test with Yates correction. In all tests, we considered the significance level of $5 \%$. For the risk assessment, we chose the calculation of prevalence rates.

The study was approved by the Research Ethics Committee of the State University of Londrina (UEL), under register number 131/2011, as the Certificate of Presentation for Ethics Acceptance - No. CAAE 0123.0.268.268-11.

\section{RESULTS}

The process of convening the study participants was hampered by the incompleteness of annotations, and outdated and incorrect records, mainly related to addresses and phone numbers. So, on average, two telephone calls were made to each patient who was registered in the medical records (around 3000 calls), and approximately 300 people (20\%) contacts were invited by community health workers. Thus, to achieve the sample approximately three times the number of dia- 
betics predicted at baseline was contacted; there was therefore no loss.

Of the 1,515 patients analyzed, $63 \%$ were female. The average age was 66.1 years (standard deviation $=10.2$ years) and a median of 66 years. Regarding ethnic pattern, 53.6\% were self-reported white, and most of them had a partner (66.3\%).

Regarding the level of education, functional illiterate individuals (41.1\%) and ones with primary education (39.8\%) were predominant, while only $8.3 \%$ had higher education. For the economic classification, the majority was made up of middle class (C) individuals, totaling $61.4 \%$ of sample.

A foot at risk of ulceration was identified in $12.3 \%$ of the population, predominantly level 2 changes $(7.1 \%)$, followed by level 1 (3.5\%) and level 3 (1.7\%).

The habit of daily drying between toes was reported by $62.2 \% ; 20.7 \%$ reported never doing it and $17.2 \%$ carried out this care sometimes. According to participants, $16.9 \%$ self-analyze feet daily, $46.2 \%$ sometimes and $36.9 \%$ never. The occasional practice of foot baths was reported by $22.2 \%$ of individuals and $9.0 \%$ did this as a daily practice. The daily or occasional habit of walking barefoot had, respectively, $6.9 \%$ and $20.9 \%$ of respondents.

Of the individuals examined, $39.4 \%$ presented inappropriate footwear during the interview. When asked about the kind of daily use footwear, $59.6 \%$ reported they were using inappropriate shoes.

Of the self-care practices, only inappropriate nail cutting was statistically significant ( $p=0.000$ ) compared to the increased risk of ulceration.

In the clinical examination of the feet, most individuals had improperly cut nails (59.9\%), and $89.4 \%$ had their feet in good hygienic conditions. Onychomycosis was found in $64.1 \%$ of diabetics, increasing the risk of ulceration ( $p=0.000)$. The presence of interdigital mycosis was a risk factor for ulceration ( $p=0.031$ ), affecting $16.8 \%$ of subjects, as shown in Table 1.

Table 1. Distribution of dermatologic abnormalities, according to the classification of risk of ulceration in the feet of type 2 diabetic patients, enrolled in Basic Health Units in Londrina (PR). Londrina, Paraná, Brazil, 2012.

\begin{tabular}{lc}
\hline \multirow{2}{*}{ Dermatologic Abnormalities } & $\begin{array}{c}\text { Feet Ulceration } \\
\text { Risk ( } \mathbf{n}=\mathbf{1 . 5 1 5})\end{array}$ \\
\cline { 2 - 2 } & (\%) Level 0 \\
\hline Onychomycosis & 83,8 \\
\hline Yes & 94,9 \\
\hline No & \\
\hline Interdigital mycosis & 84,3 \\
\hline Yes & 88,5 \\
No & \\
\hline Calluses & 86,9 \\
\hline Yes & 88,3 \\
\hline No & 89,1 \\
\hline Moisture of feet & 85,5 \\
\hline Normal & 81,8 \\
Anhidrosis & \\
Hyperhidrosis & \\
*p<0,05 & \\
Source: Author's research &
\end{tabular}

The callus was identified in $33.3 \%$ of subjects, with $21.2 \%$ located in the rearfoot, $17.6 \%$ in the forefoot and $0.9 \%$ in the midfoot. Despite the lack of statistical significance ( $p=0.457$ ) in simple intersection, when the variable foot classification was re-established as low and high risk, diabetics with calluses showed a risk of ulceration $1.6 \%$ higher compared to those without it. Regarding feet moisture, 34.5\% had anhidrosis (dryness) and $0.7 \%$ hyperhidrosis (excessive moisture).

Table 2 shows the vascular, orthopedic and neurological alterations found in the feet of the studied population. 
Table 2. Distribution of vascular, orthopedic and neurological alterations according to the risk classification of diabetic foot ulceration in type $2 \mathrm{DM}$ patients, registered in the Basic Health Units in Londrina (PR), Brazil, 2012

\begin{tabular}{|c|c|c|c|c|c|}
\hline \multirow{3}{*}{ Variables } & \multicolumn{5}{|c|}{$\begin{array}{l}\text { Feet Ulceration Risk } \\
(n=1.515)\end{array}$} \\
\hline & \multicolumn{4}{|c|}{ (\%) } & \multirow{2}{*}{$\begin{array}{c}P \\
\text { value }\end{array}$} \\
\hline & $\begin{array}{c}\text { Level } \\
0 \\
\end{array}$ & $\begin{array}{c}\text { Level } \\
1 \\
\end{array}$ & $\begin{array}{c}\text { Level } \\
2 \\
\end{array}$ & $\begin{array}{c}\text { Level } \\
3 \\
\end{array}$ & \\
\hline \multicolumn{5}{|c|}{ Dorsalis pedis pulse } & $0,000^{*}$ \\
\hline Palpable & 91,5 & 2,9 & 4,7 & 0,9 & \\
\hline Reduced & 68 & 8,6 & 18,3 & 5,1 & \\
\hline $\begin{array}{l}\text { Non palpa- } \\
\text { ble }\end{array}$ & 79,5 & 0 & 15,7 & 4,8 & \\
\hline \multicolumn{5}{|l|}{ Tibial pulse } & $0,000^{*}$ \\
\hline Palpable & 92,8 & 3,3 & 3,1 & 0,8 & \\
\hline Reduced & 74,2 & 6,3 & 16,7 & 2,7 & \\
\hline $\begin{array}{l}\text { Non palpa- } \\
\text { ble }\end{array}$ & 75 & 1,5 & 18,4 & 5,1 & \\
\hline \multicolumn{5}{|c|}{ Capillary refill } & $0,000^{*}$ \\
\hline Normal & 88,4 & 3,6 & 6,5 & 1,5 & \\
\hline Altered & 71,9 & 1,8 & 21,1 & 5,3 & \\
\hline \multicolumn{5}{|c|}{ Bony prominences } & $0,000^{*}$ \\
\hline Yes & 69,7 & 0 & 22,5 & 7,9 & \\
\hline No & 88,9 & 3,7 & 6,1 & 1,3 & \\
\hline \multicolumn{5}{|l|}{ Claw toes } & $0,000^{*}$ \\
\hline Yes & 69,9 & 1,4 & 23,1 & 5,6 & \\
\hline No & 89,7 & 3,7 & 5,4 & 1,2 & \\
\hline \multicolumn{5}{|c|}{ Hammer toes } & $0,000^{*}$ \\
\hline Yes & 83,8 & 1,2 & 12,5 & 2,5 & \\
\hline No & 88 & 3,6 & 6,8 & 1,6 & \\
\hline \multicolumn{5}{|c|}{ Hallux valgus } & $0,000^{*}$ \\
\hline Yes & 86,3 & 0,8 & 10,6 & 2,3 & \\
\hline No & 88,3 & 4,4 & 5,9 & 1,4 & \\
\hline \multicolumn{5}{|c|}{ Loss of protective sensation } & $0,000^{*}$ \\
\hline Yes & 98,6 & 0,8 & 0,2 & 0,3 & \\
\hline No & 1,5 & 79,2 & 97,2 & 84 & \\
\hline
\end{tabular}

As to vascular alterations, it was found that the pedal pulse was decreased in $13.0 \%$ of the diabetic patients and absent in 5.5\%. The posterior tibial pulse was lower in $14.6 \%$, and absent in $12.9 \%$ of the patients. The decline and absence of pulse is directly related to increased risk of foot ulceration $(p=0.000)$.

Of the orthopedic disorders, we found hallux valgus $(25.6 \%)$, claw toes $(9.4 \%)$, bony prominences (5.9\%) and hammer toes (5.3\%). The loss of protective sensation in the feet was found in $12.3 \%$ of diabetics, and for the left foot it was $0.1 \%$ higher than for the right foot.

Table 3 presents the prevalence ratio (PR) associated with increased risk factors of ulceration in feet.

Table 3. Prevalence ratio associated with increased risk of ulceration factors in the feet of type 2 diabetic patients, registered in the Basic Health Units in Londrina (PR). Londrina, Paraná, Brazil, 2012.

\begin{tabular}{|c|c|c|c|}
\hline Factor & PR & IC $95 \%$ & $\begin{array}{c}P \\
\text { Value }\end{array}$ \\
\hline Daily used footwear & 0,631 & $0,441-0,902$ & $0,008^{*}$ \\
\hline Improper nail cutting & 1,961 & $1,313-2,928$ & $0,000^{*}$ \\
\hline Onychomycosis & 3,031 & $1,894-4,853$ & $0,000^{*}$ \\
\hline Interdigital mycosis & 1,674 & $1,096-2,555$ & $0,014^{*}$ \\
\hline Altered capillary refill & 4,093 & $2,204-7,602$ & $0,0008^{*}$ \\
\hline Claw toes & 5,658 & $3,717-8,614$ & $0,000^{*}$ \\
\hline Hammer toes & 1,934 & $1,018-3,673$ & $0,040^{*}$ \\
\hline Hallux valgus & 1,885 & $1,299-2,736$ & $0,001^{*}$ \\
\hline Bony prominences & 5,479 & $3,344-8,976$ & $0,000^{*}$ \\
\hline $\begin{array}{l}\text { Loss of protective } \\
\text { sensation }\end{array}$ & 380,472 & $\begin{array}{l}170,491- \\
849,073\end{array}$ & $0,000^{*}$ \\
\hline
\end{tabular}

Only dichotomous variables were used in the analysis of PR. The three main factors that most influenced to risk of ulceration in the feet were the loss of protective sensation, claw toes and bony prominences.

\section{DISCUSSION}

The predominance of females (63\%) in this study reflects the reality of Brazilian society. The country's culture is permeated by socio- 
-cultural and institutional barriers that result in low demand and adhesion of men to primary care services. The male is seen as invulnerable, and getting sick can be interpreted as a sign of weakness, and there is also the fear of the diagnosis of a serious condition. The health services themselves give little emphasis to health care for the man, with inflexible attendance schedules considering that most of male patients are in a productive life stage. These factors make males more vulnerable to complications of chronic degenerative diseases. In this context, the Policy for Integral Attention to Men's Health, recently implemented in Brazil, was structured with the goal of improving access by the male population to health services and the resolution of the actions developed for this population ${ }^{(8)}$.

The average age of 66.1 years found in this study confirms aging as a risk factor for DM and increases predisposition to the development of its complications. Aging causes a series of changes in the vascular, neurological and musculoskeletal systems that predispose peripheral vascular disease and neuropathy, which are the main factors for the development of ulcers and amputations of lower limbs ${ }^{(4)}$.

We observed that $66.3 \%$ of study participants had a partner, which constitutes an important factor influencing the adhesion to treatment, both as a stimulus to the adoption of a healthy lifestyle and as assistance to perform self-care actions which may be limited by physical disabilities resulting from age and deterioration caused by diabetes ${ }^{(4)}$.

A low level of education predominated among participants. This factor complicates their understanding of the guidelines set by the health team, because the lower the educational level, the less access to information and ability to understand. The low educational qualification creates demands for nurses, as the primary health educators, developing health education strategies that allow the sufferer of DM a better understanding of the disease, favoring greater autonomy and attention to treatment ${ }^{(9)}$.

The prevalence of a foot at risk of ulcers found during this research was high (12.3\%), considering the study which shows the prevalence of foot ulcers in more than $4 \%$ of diabetic patients; if control and foot care measures are not instituted, this rate may reach up to $12 \%{ }^{(1)}$. Therefore, regular inspection of the feet of diabetic patients and the categorization of associated risk of ulceration are considered important impact factors on reducing the occurrence of injuries in the feet and lower limb amputations ${ }^{(10)}$.

The classification of risk of ulceration level in the feet allows us to determine the approaches to be taken and the frequency with which the feet of the diabetic patients should be examined, so that there is a systematic and periodic monitoring of this population. These precautions minimize the risk of ulceration and enable analysis of the behaviors and advice proposed, and adequacy of treatment according to the progression of the disease ${ }^{(7)}$.

As for self-care habits with feet, we observed that the variables drying between toes, self-exam feet, foot baths, walking barefoot, shoes used daily and at the time of interview and foot hygiene, although not statistically significant, are clinically important because they expose the patient to risk. Although the exam of the feet is the responsibility of health professionals, educational activities with the goal of increasing the motivation and the ability for the self-evaluation should be developed so that diabetics can recognize potential problems and precautions to be taken ${ }^{(11)}$.

In this research, interdigital mycosis and onychomycosis showed statistical correlation with the risk of ulceration. These may be related to self-care and hygiene practices, individual usage and daily change of socks, proper hy- 
giene of shoes, individual use of instruments for nail care and the habit of drying feet. These alterations must be dealt with, and diabetic patients must receive proper guidance, since it can be the entrance of infections that worsen the situation ${ }^{(1)}$.

Interdigital mycosis also is closely related to the habit of not drying between the toes, as the humidity present betweens toes favors the development of fungal infections ${ }^{(1)}$. This problem may occur due to the difficulty for patients to reach their feet and absence of people that can help diabetes patients with self-care.

One of the major challenges for the early diagnosis of diabetic individuals at risk of developing diabetic foot is an improper or unperformed simple test. The lack of the exam may happen due to ignorance of its importance and/or which alterations should be observed, physical limitations resulting from decreased visual acuity, obesity, advanced age, and lack of sense of the foot as an important limb and vulnerable to changes that may compromise quality of life ${ }^{(12)}$.

The reported use of inappropriate footwear at home was higher than the use identified at the time of interview. The type of shoe can be crucial in the prevention and treatment of ulcers and to reduce plantar pressure; improperly used shoes is a leading cause of foot injuries ${ }^{(1,3)}$.

The anhidrosis identified in $34.5 \%$ of diabetics shows the presence of autonomic neuropathy, which predisposes to the appearance of calluses and cracks. Neuropathy causes loss of basal vascular tone and in the sweat glands, resulting in increased blood flow and dry skin (anhidrosis), respectively ${ }^{(1,13)}$.

Orthopedic disorders found in this study, in ascending order of importance, were claw toes, bony prominences, hammer toes and hallux valgus. Orthopedic and muscular changes are caused by the interaction of neuropathic, in- flammatory, and metabolic factors, and others associated with obesity and improper footwear, the main factor to motor neuropathy ${ }^{(4)}$. These elements cause changes in walking and create new pressure points, hindering the use of common footwear and consequently increasing the risk of ulceration ${ }^{(13)}$. The use of therapeutic footwear is still expensive and out-of-reach for the population. Though available in the public health system of Londrina city, there is not enough to meet the demand.

We identified that sensory alteration was present in $12.3 \%$ of the sample, increasing the risk of ulceration by more than 380 times. The loss of sensation in the feet is more common in diabetic patients ${ }^{(14)}$. Sensory alterations affect pain sensitivity, the perception of pressure, temperature and proprioception. This loss of protective sensation exposes diabetic patients to extrinsic factors, such as insensibility to foreign bodies, precipitated by intrinsic factors.

The feet of diabetics have their own characteristics, capable of turning a simple injury into the amputation of a limb or a threat to patient's life itself. The education of the patient and his family, addressing themes as foot hygiene, nail care, and use of proper footwear, are all crucial to reduce the risk of injury and the formation of ulcers.

A study that examined the knowledge of patients with diabetes mellitus about their treatment, five years after the completion of an educational program, identified that the knowledge about the disease and self-care were incorporated by the participants of the group, but the authors recommend continuous reinforcement about the gains earned by the acquisition of knowledge in order to provide a lasting adoption of habits ${ }^{(15)}$.

Strategies and programs of education for self-care of feet can improve procedures for diabetic care, reducing lower limb morbidity. 
Nevertheless, most patients do not receive inspection or regular foot care in health services where they monitor the disease.

Education practices must consider the reality of the subject, and aim to provide knowledge to promote independent individuals who can be active in the care process. Any intervention to change health habits and lifestyles of patients with chronic diseases involves changing the individual, cultural, social and community behaviors and, for this to occur, that learning is essential(16).

The nurse plays an important role in health education and is responsible for articulating the scientific knowledge and the individual or collective common practice, and for showing alternatives applicable to the realities presented, favoring the change in lifestyle and the development of autonomy in self-care ${ }^{(17)}$.

\section{CONCLUSION}

The prevalence of foot ulceration at risk identified in this study is considered high, and is related to several skin, vascular, and neuropathic factors permeated by the self-care factor. The prevalence of grade 2 alterations shows the association of more than one risk factor for ulceration, in addition to neuropathy.

Prevention of abnormalities in the feet of diabetics involves many factors, from aspects related to maintenance of glycemic control to specific foot care actions.

The nurse, as the coordinator of BHUs and their respective teams, is responsible for articulating the various components of primary health care services, team members and their expertise to conduct the treatment in a multidisciplinary way, meeting the needs of diabetics.

Self-care practices are the key to preventing foot injuries; therefore, it is necessary to deve- lop educational activities that provide greater understanding of the complications that can affect lower limbs and the care actions that can prevent them.

Precautions that can reduce the development of foot injuries, such as drying between toes, always avoiding walking barefoot, cutting the nails following the contour of the fingertip and making use of appropriate footwear, are easy to implement, but adopting these habits requires a change of life and routines, hindering its accession.

Again, the intervention of the nurse is needed as a facilitator of this process by periodical and continuous monitoring in order to develop alternatives with the diabetic patients that facilitate their adherence to necessary care.

Health education should be the main focus for prevention of feet ulcers and amputations; most of their risk factors are related to lifestyle habits. Therefore, so that the measures can be effective, the active participation of people with diabetes through self-care is essential.

Health professionals, especially nurses, have the task of developing continuing education activities in health and stimulating interest in caring for the foot, so that diabetic patients can understand the importance that these limbs have before suffering some irreversible damage.

The limitation of this study occurred mainly during the call and data-access process of the participants, which was hampered by the incompleteness of information, outdated and incorrect records - mainly related to the address, phone number, clinical data and test results. Due to these factors, many diabetics who fit the criteria for exclusion were called and evaluated, but their data were not included in this research. 


\section{REFERENCES}

1. International Working Group on the Diabetic Foot (Nederlands). International Consensus on the Diabetic Foot. Amsterdam: International Working Group on the Diabetic Foot; 2011.

2. American Diabetes Association (USA). Standards of Medical Care in Diabetes. Diabetes Care. 2012; 5(Suppl 1):11-63.

3. Sociedade Brasileira de Diabetes (Brasil). Diretrizes da Sociedade Brasileira de Diabetes 20132014. Rio de Janeiro: A. Araújo Silva Farmacêutica; 2013.

4. Ministério da Saúde (Brasil), Secretaria de Atenção à Saúde, Departamento de Atenção Básica. Diabetes Mellitus. Caderno de Atenção Básica. Brasília: Ministério da Saúde; 2006.

5. Bortoletto MSS. Risco de ulceração em pés de portadores de diabetes mellitus em Londrina, Paraná: caracterização do cuidado na atenção básica, prevalência e fatores associados. [dissertação] Londrina: Universidade Estadual de Londrina; 2010.

6. González CP. Monofilamento de Semmes-Weinstein. Diabetes práctica. Actualización y habilidades en Atención Primaria. 2010; 1(1):8-19.

7. Londrina. Prefeitura do Município. Autarquia Municipal de Saúde. Protocolo clínico de saúde do adulto: hipertensão arterial, diabetes e dislipidemia. Londrina: Secretaria Municipal de saúde; 2006.

8. Leal AF, Figueiredo WS, Nogueira da Silva GS. Charting the Brazilian Comprehensive Healthcare Policy for Men (PNAISH), from its formulation through to its implementation in local public health services. Ciênc saúde coletiva. 2012; 7(10):2607-16.

9. Baggio SC, Sales CA, Marcon SS, Santos AL. Percepção de pessoas com diabetes sobre a doença e os motivos de rehospitalização: estudo descritivo. Online braz j nurs [Internet]. 2013 Sept [cited 2014 Feb 03]; 12 (2): 501-10. Available from: http://www.objnursing.uff.br/index.php/ nursing/article/view/4080
10. Caiafa JS, Castro AA, Fidelis C, Santos VP, Silva ES, Sitrângulo Jr CJ. Atenção integral ao portador de pé diabético. J vasc bras. [internet]. 2011 [cited 2014 Feb 01]; 10(4 Suppl 2): 1-32. Available from: http://www.scielo.br/scielo.php?script=sci_artte xt\&pid=S1677-54492011000600001

11. Cisneros LL, Gonçalves LAO. Educação terapêutica para diabéticos: os cuidados com os pés na realidade de pacientes e familiares. Ciênc. saúde coletiva [internet]. 2011 Jan [cited 2014 Feb 01] ; 16( Suppl 1 ): 15051514. Available from: http://www.scielosp. org/scielo.php?script=sci_arttext\&pid=S141381232011000700086\&lng=en.

12. Pérez RMC, Godoy S, Mazzo A, Nogueira PC, Trevizan MA, Mendes IAC. Cuidado com os pés diabéticos antes e após intervenção educativa. Enferm glob. 2013; 12(29):43-52.

13. Rizzo S. Fisiopatologia do pé diabético e da úlcera neuropática. In: Batista F, Organizador. Uma abordagem multidisciplinar sobre o pé diabético. São Paulo: Andreoli; 2010.

14. Borges FA, Cardoso HSG. Avaliação sensório-motora do tornozelo e pé entre idosos diabéticos e não diabéticos. Rev Bras Geriatr Gerontol. 2010; 13(1): 93-102.

15. Chagas IA, Camilo J, Santos MA, Rodrigues FFL, Arrelias CCA, Teixeira CR et al. Patients' knowledge of Diabetes five years after the end of an educational program. Rev esc enferm USP [Internet]. 2013 Oct [cited 2014 Feb 01]; 47(5): 1137-1142.Available from: http://www.scielo.br/scielo.php?script=sci_arttext\&pid=S008062342013000501137\&lng=en.

16. Martins MJR, José HMG. Evaluation of risk of type 2 diabetes in primary health care. Rev enferm UFPE [Internet] 2013 [cited $2014 \mathrm{Fev}$ 03]; 7(10):5896-906. Available from:http://www. revista.ufpe.br/revistaenfermagem/index.php/ revista/article/view/4614/pdf_3602

17. Borba AKOT, Marques APO, Leal MCC, Ramos RSPS. Práticas educativas em diabetes Mellitus: revisão integrativa da literatura. Rev Gaúcha Enferm. 2012; 33(1):169-76. 
All authors participated in the phases of this publication in one or more of the following steps, in According to the recommendations of the International Committee of Medical Journal Editors (ICMJE, 2013): (a) substantial involvement in the planning or preparation of the manuscript or in the collection, analysis or interpretation of data; (b) preparation of the manuscript or conducting critical revision of intellectual content; (c) approval of the versión submitted of this manuscript. All authors declare for the appropriate purposes that the responsibilities related to all aspects of the manuscript submitted to OBJN are yours. They ensure that issues related to the accuracy or integrity of any part of the article were properly investigated and resolved. Therefore, they exempt the OBJN of any participation whatsoever in any imbroglios concerning the content under consideration. All authors declare that they have no conflict of interest of financial or personal nature concerning this manuscript which may influence the writing and/or interpretation of the findings. This statement has been digitally signed by all authors as recommended by the ICMJE, whose model is available in http://www. objnursing.uff.br/normas/DUDE_eng_13-06-2013.pdf
Received: 02/19/2014

Revised: 08/11/2014

Approved: 09/02/2014 